\title{
Changes of histopatological images in vertebra discuss after cigarette exposure: using experimental test on the model of russ exposed to cigarette
}

\author{
Gabriel Klemens Wienanda ${ }^{\mathrm{a}}$, Pranajaya Dharma Kadar ${ }^{\mathrm{b}}$, Iman Dwi Winanto ${ }^{\mathrm{c}}$ \\ ${ }^{a}$ Resident of Orthopaedic \& Traumatology, Faculty of Medicine University of Sumatera Utara/ Haji Adam Malik General Hospital-Medan \\ ${ }^{b}$ Consultant of Orthopedics \& Traumatology, Spine Division, Faculty of Medicine, University of North Sumatra / Haji Adam Malik Hospital- \\ Medan \\ ${ }^{c}$ Consultant of Orthopedics \& Traumatology, Pediatric Division, Faculty of Medicine, University of North Sumatra / Haji Adam Malik Hospital- \\ Medan
}

\begin{abstract}
Objective: In this study, the researchers were interested in seeing the relationship between smoking and disc degeneration as seen in the histology of mouse intervertebral discs using experimental studies.

Methods : This type of research is experimental research. White rats were divided into 3 groups, namely the first group was euthanized before the exposure to cigarette smoke $(n=5)$, the second group was euthanized on the 14th day after exposure to cigarette smoke $(n=5)$, and the third group was euthanized on the 28 th day after exposure. cigarette smoke $(\mathrm{n}=5)$. At the appointed time, a sample is taken for histological examination of the vertebral discs.

Result: Based on statistical results, there were significant changes in Annulus fibrosus in mice exposed to cigarettes on day 14 and day 28 .

Conclusions: There was a significant change in the histopathological features of the vertebral disc after exposure to cigarette smoke. This proves that cigarette smoke can cause lower back pain and can be used as an educational material for the community. Further research is needed to deepen this causal relationship.
\end{abstract}

Keywords: Type your keywords here, separated by semicolons ;

\section{Introductions}

Low back pain is rarely associated with mortality, but it is one of the biggest causes of morbidity in the world. Lower back pain is closely associated with degenerative intervertebral disc disease. The prevalence of smoking continues to increase in both men and women in Indonesia. In several studies reported that smoking is closely related to low back pain, several epidemiological studies have shown that there are risk factors that smoking can cause low back pain. It has been found that smoking can increase the risk of damage to intervertebral discs. By interfering with the metabolism of these discs with the hypothesis that smoking reduces circulation of blood around the intervertebral discs and reduces the exchange of nutrients and metabolites. In this study, the researchers were interested in seeing the relationship between smoking and disc degeneration as seen in the histology of mouse intervertebral discs using experimental studies.

\section{Methods}

Before the study the researcher applied for a research permission, consent was obtained from the research subject and the Ethics Committee of the Faculty of Medicine, University of North Sumatra, Medan. The population of this study was adult research wistar rats weighing 100-200 grams. These mice were obtained from the Integrated Laboratory of the USU Faculty of Pharmacy. 
This type of research is experimental research and uses a randomized controlled design with a One Group Pretest Posttest design. This research was conducted from September - November 2019 at the Integrated Laboratory of the Faculty of Pharmacy, University of North Sumatra (USU).

The research subjects were 15 individuals. White rats were divided into 3 groups, namely the first group was euthanized before the exposure to cigarette smoke $(n=5)$, the second group was euthanized on the 14th day after exposure to cigarette smoke $(n=5)$, and the third group was euthanized on the 28th day after exposure. cigarette smoke $(n=5)$. Subjects wanted for the study were taken from all affordable populations that met the inclusion criteria, namely male Wistar rats that were healthy, had no fever $\left(38.3-39.4^{\circ} \mathrm{C}\right)$, weighed $100-200$ grams, and were 2-3 months old.

The sample size calculation in this study was obtained based on the formula $(n-1)(k-1) \geq 15$. Where $n$ is the number of samples per group, and $\mathrm{k}$ is the number of treatment groups. If the calculation is done $(1)(n-1)(1-1)$ $\geq 15$, then $n \geq 15$ is obtained. Treatment and control rats received food and drink given ad libitum in the form of pellets and rat feed and incubated for 8 weeks and carried out clinical examinations, namely observing daily activity, signs of infection, measuring temperature and body weight every three days, as well as control mice. Rats will be given smoke for a duration of 4 minutes then given free air ventilation for 5 minutes with exposure to cigarette smoke using a type of filter cigarette containing $16 \mathrm{mg}$ TAR and 1.8 nicotine, cigarettes are given as many as 20 cigarettes per day for the duration of the time specified.

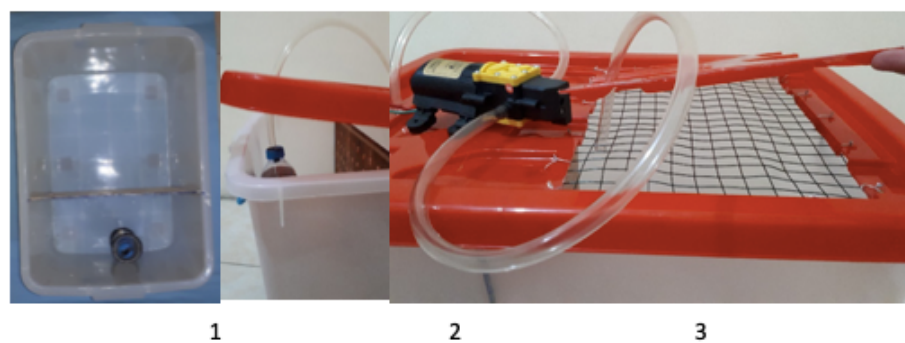

Figure 1: Image from the above, distribution of the cigarette holder and the rat holder

Figure 2: The suction hose from the bottle where the cigarette is placed, the hose is directed to the suction machine.

Figure 3: Hose into the rat container to provide cigarette smoke

At the specified time, samples were taken for histological examination of degenerative discs, then the mice were euthanized. The rats were then necropsed after first being disinfected with $70 \%$ alcohol. The cutting was done to remove the 11th, 12th, and 1st lumbar vertebrae, which were then separated by a disarticulation procedure of 2 facet joints and 1 intervertebral joint using a scapula to obtain the vertebrae. The examination material obtained in this procedure is in the form of 1 pot containing bone tissue and the disc is fixed in a $10 \%$ neutral formalin buffer. Bone tissue blocks were cut using a microtome with a thickness of 3-5 microns, glued to the slide and incubated in an incubator for 1 night. Staining begins with rehydration of xylol levels 1, 2 and 3, put into absolute alcohol 3 times, followed by alcohol $96 \%, 90 \%, 80 \%$ and $70 \%$, then with water. Stained with hematoxylin solution for 3 minutes, washed with tap water for 5 minutes then rinsed with distilled water followed by staining using eosin solution for 1 minute. Put in alcohol 70\%, 80\%, 90\%, 96\% and absolute alcohol 3 times and into xylol 3 times, given a fixator and covered with a cover glass then observed under a microscope. at the Anatomical Pathology Laboratory of $\mathrm{H}$. Adam Malik Hospital, Medan. The results of the histopathological examination of the tissue will be subjected to a degenerative grading examination as follows.

1. Degenerative degree of annulus fibrosus

- 0 : Normal

- 1: No protrusion on the edge of the annulus fibrosus (Mildly Serpentine)

- 2: A little protrusion on the edge of the annulus fibrosus (Moderately Serpentine)

- 3: Marked protrusion on the edge of the annulus fibrosus (Severely Serpentine)

- 4: Marked bulging and tearing at the periphery of the annular fibrosis (Severely Serpentine and Ruptured)

- 5: Gap / separation of the annulus fibrosus (Indistinct) 
2. Degenerative degree of nucleus pulposus

- 0: Normal

- 1: Thickening of the nucleous pulposus (Condensed)

- 2: Few cells like chondrocytes and the nucleus pulposus matrix (Existence of chondrocyte like cells, residual NP matrix)

- 3: many cells like chondrocytes (Global existence of chondrocyte-like cells)

- 4: slight change to cartilaginous fibrous tissue (Mildly replaced by fibrous cartilaginous tissue)

- 5: moderate - severe changes to cartilaginous fibrous tissue (Moderately or severely replaced by fibrous cartilaginous tissue)

The histologipatology examination data of the disc is in the form of soft copy (file) accompanied by a photo, stored in a closed envelope and labeled. The sample data are arranged in a distribution table. For bivariate data, data normality tests will be carried out using the Shapiro-Wilk test, because the number of samples is less than 50.If the results of the normality test are obtained $\mathrm{p}>0.05$ means that the data is normally distributed, then the data will be analyzed using ANOVA, if the data is not normally distributed then will be carried out the Kruskal Wallis test. Data analysis using SPSS version 15 .

\section{Results}

The research subjects were 15 white rats divided into 3 groups, namely the first group was euthanized before the cigarette smoke exposure treatment consisted of five rats, the second group was euthanized on the 14th day after being exposed to cigarette smoke as many as five rats, and the third group was euthanized on the second day. 28 after being exposed to cigarette smoke were five rats.

Table 1. Characteristics of Vertebral Discs in Research Subjects

\begin{tabular}{|l|l|l|l|}
\hline No & $\begin{array}{c}\text { Mice } \\
\text { Euthanized } \\
\text { on Day- }\end{array}$ & $\begin{array}{c}\text { Annulus fibrosus Histological } \\
\text { assessment Grading }\end{array}$ & $\begin{array}{c}\text { Nukleus pulposus Histological } \\
\text { assessment Grading }\end{array}$ \\
\hline 1 & 0 & Normal & Normal \\
\hline 2 & 0 & Normal & Normal \\
\hline 3 & 0 & Normal & Normal \\
\hline 4 & 0 & Normal & Normal \\
\hline 5 & 0 & Normal & Normal \\
\hline 6 & 14 & Moderately Serpentine & $\begin{array}{c}\text { Existence of chondrocyte like cells, } \\
\text { residual NP matrix }\end{array}$ \\
\hline 7 & 14 & Mildly Serpentine & Normal \\
\hline 8 & 14 & Mildly Serpentine & Normal \\
\hline 9 & 14 & Mildly Serpentine & Condensed \\
\hline 10 & 14 & Moderately Serpentine & Condensed \\
\hline 11 & 28 & Indistinct & $\begin{array}{c}\text { Moderately or severely replaced by } \\
\text { fibrous cartilaginous tissue }\end{array}$ \\
\hline 12 & 28 & Moderately Serpentine & Condensed \\
\hline 13 & 28 & Indistinct & $\begin{array}{c}\text { Moderately or severely replaced by } \\
\text { fibrous cartilaginous tissue }\end{array}$ \\
\hline 14 & 28 & Indistinct & $\begin{array}{c}\text { Moderately or severely replaced by } \\
\text { fibrous cartilaginous tissue }\end{array}$ \\
\hline
\end{tabular}




\begin{tabular}{|l|l|l|l|}
\hline 15 & 28 & Indistinct & $\begin{array}{c}\text { Moderately or severely replaced by } \\
\text { fibrous cartilaginous tissue }\end{array}$ \\
\hline
\end{tabular}

Based on the data obtained, the results of the control vertebral disc (before exposure to cigarette smoke) found that all of the annulus fibrosus and nucleus pulposus were within normal limits. Results Vertebral discs in mice that were euthanized on day 14 were exposed to cigarette smoke, it was found that in mice one and five there was a change in the histological grading of Annulus fibrosus to Moderately Serpentine and histological grading of Nucleus pulposus to Existence of chondrocyte like cells, residual NP matrix, in the second mouse, third, and fourth, there was a change in the histological grading of Annulus fibrosus to Mildly Serpentine. In mice two and three there were no changes in the histological grading of the nucleus pulposus. In the fourth and fifth mice, there were changes in the histological grading of the nucleus pulposus to become condensed. Vertebral discs in mice that were euthanized on the 28th day of exposure to cigarette smoke, were found in mice one, three, four, and five, there was a change in the histological grading of Annulus fibrosus to indistinct and histological grading of the nucleus pulposus to Moderately or severely replaced by fibrous cartilaginous tissue, at The second mice had histological changes in Annulus fibrosus grading to Moderately Serpentine and histological grading of Condensed nucleus pulposus.

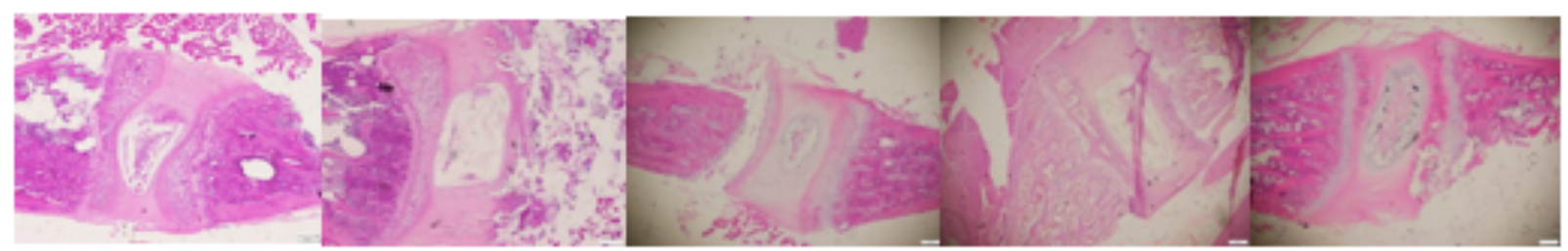

Figure 4. Histopathological overview of the control subject's tissue (day 0)

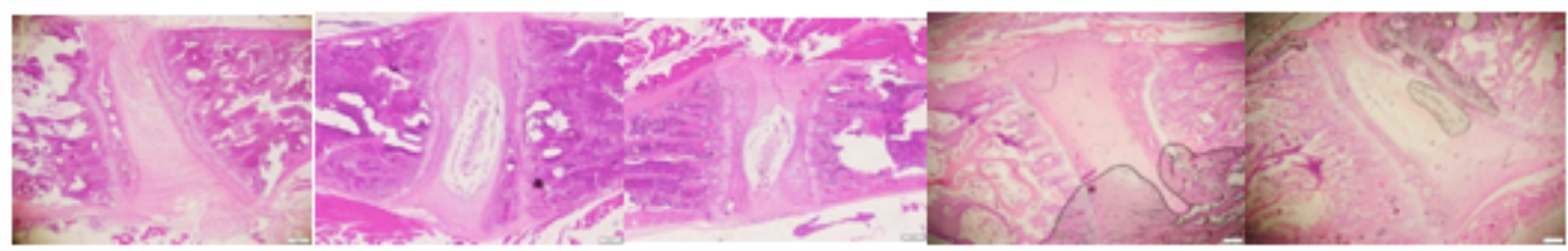

Figure 5. Histopathological overview of the subject's tissue on day 14

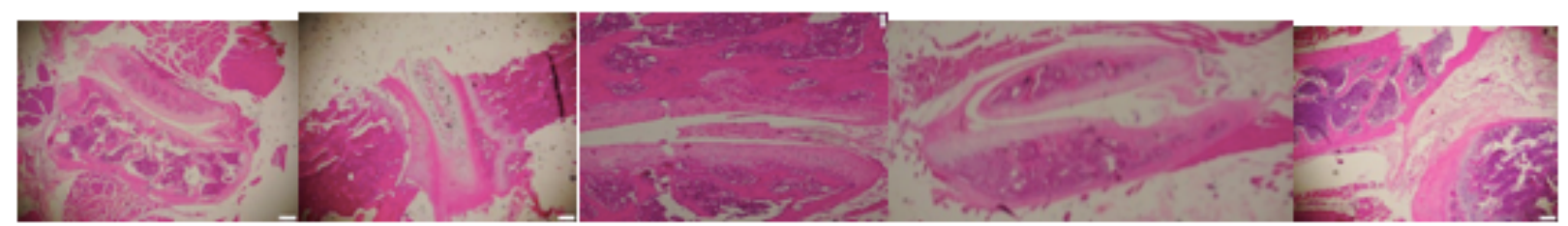

Figure 6. Histopathological overview of the subject's tissue on day 28 
Based on the distribution, Group A: was euthanized before the exposure to cigarette smoke, Group B: wånoo euthanized on the 14th day after exposure to cigarette smoke, Group C: was euthanized on the 28th day after being exposed to cigarette smoke. The data found that the results of the study showed changes in Annulus fibrosus in group B grade $1(60 \%)$, grade $2(40 \%)$ as well as in group C grade $2(20 \%)$ and grade $5(80 \%)$. The significance value ( $\mathrm{Sig}$ ) obtained is 0.002 . This shows that statistical results there are significant changes in Annulus fibrosus in mice exposed to cigarettes on day 14 and day 28.

From the data it was found that the results of the study showed changes in the nucleus pulposus in group B grade $0(40 \%)$, grade $1(40 \%)$, grade $2(20 \%)$ and in group C grade $1(20 \%)$ and grade $5(80 \%)$. The significance value (Sig) obtained is 0.005 . This shows that statistical results there are significant changes in the nucleus pulposus in mice exposed to cigarettes on day 14 and day 28.

There is a significant difference between Group B and Group C where the $p$ value is $<0.05$. The following results show that the results of the study indicate changes in the Annulus fibrosus and Nucleus Pulposus.

\section{Discussions}

From the results of this study there were significant differences between Group B (rats were euthanized on day 14 after exposure to cigarette smoke) and Group C (rats were euthanized on day 28 after exposure to cigarette smoke) where there were changes in Annulus fibrosus and nucleus pulposus in these mice. This is in accordance with research conducted by Ande M. Jakoi, et al (2016) where in this study it was stated that the population who smoking experienced disc degeneration more than the population who did not smoking.

This study is also in accordance with the study of Schumann, et al. Showed that men who smoked for between twenty and forty packs per year showed a significantly increased ratio for lumbar intervertebral herniation, a higher risk of lumbar intervertebral herniation seen in women who smoked for between eight years. and twenty years. Lumbar intervertebral herniation is confirmed by MRI or computed tomography (CT).

Then in research conducted by Nakahashi M, et al. (2019) using mice that were treated as passive smokers, found changes in the structure of the fibrous tissue in the nucleus pulposus. However, in the annulus fibrosus there was no significant structural change. This occurs due to degradation of the connective tissue type 2 and proteoglycans, which affects the support structure of the nucleus pulposus. This fact can support the results of this study.

The expression of the ADAMTS5 protein plays a role in disc degeneration. In a study conducted by Kevin Ngo, et al (2017) using mice with ADAMTS5 protein deficiency conditions and then given chronic exposure to cigarette smoke, an increase in ADAMTS5 protein expression was obtained. Cigarette smoke can also cause loss of proteoglycan tissue in the disc. However, the study did not mention how the histological picture was in these mice.

This condition can happened because there are two theories that can cause intervertebral disc damage. In the first theory, it is stated that the malnutrition mechanism in the disc caused directly by tobacco substances causes anoxia and vascular disorders. This state of malnutrition leads to disc degeneration and inhibition of vascularity to the disc has a role in the occurrence of this malnutrition. In one animal study, there was decreased blood flow to the vertebrae after nicotine administration. An increase in the concentration of carbon monoxide in the blood causes a decrease in oxygen bound to hemoglobin, thereby disrupting the distribution of nutrients in the intervertebral discs.

Meanwhile, based on the second theory, smoking can cause changes in the viability and activity of cells in the intervertebral discs. Microscopically, the intervertebral disc cells that were exposed directly to cigarettes experienced significant morphological changes, where there was an increase in the production of interleukin $1 \mathrm{~b}$ cells resulting in increased regulation of the tissue which decreased metalloproteinases. In another study, cigarette exposure to the intervertebral discs caused necrosis and fibrosis, which directly affected the nucleus pulposus and some parts of the lining of the annulus fibrosus.

From this study it was found that smoking can be a risk factor for the occurrence of histopathological changes in intervertebral discs and causing low back pain and in accordance with the hypothesis proposed by the researchers. This is also in line with the education that has been carried out by health workers to reduce 
smoking in the community in order to reduce the number of diseases that occur in the community due to smoking. This research can be applied as public education, because the causal mechanisms are similar between mice and humans anatomically and pathophysiologically. However, this study may need a longer time so that the research results are more accurate, as well as a larger number of samples to get a group of data variations from the research results. Further studies with different interventions may also be needed to assess changes in the annulus fibrosus and nucleus pulposus on exposure to cigarette smoke.

\section{Conclusions}

From the results of statistical analysis, there were changes in the histological features of the annulus fibrosus and nucleus pulposus in rats exposed to cigarettes on day 14 and day 28, where it was concluded that there were significant changes in the histopathological features of the vertebral discs after exposure to cigarette smoke.

\section{References}

Adams MA, McNally DS, Dolan P, 'Stress'distributions inside intervertebral discs. The effects of age and degeneration, 1996, J Bone Joint Surg Br, 78:965-972.

Akagi Y, Liu W, Xie K, Regulation of vascular endhotelial growth factor expression in human colon cancer by interleukin-1 beta, July 1999, NCBI publication. Br J Cancer. 80(10):1506-11.

Boubriak OA, Watson N, Sivan SS, Stubbens N, Urban JP, Factors regulating viable cell density in the intervertebral disc: blood supply in relation to disc height, March 2013, J Anat, 222(3):341-8.

Buckwalter JA, Aging and degeneration of the human intervertebral disc, 1995, spine, 20:1307-1314

Burgisser GM, Calcagni M, Bachmann E, Rabbit Achilles Tendon Full Transection Model - Wound Healing. Adhesion Formatin and Biomechanics at 3, 6 and 12 weeks post-surgery, 2016, Biology Open, DOI: 10.1242/bio.020644

Freemont AJ, Peacock TE, Goupille P, Hoyland JA, O’Brien J, Jayson M-IV, Nerve ingrowth into diseased intervertebral disc in chronic back pain, 1997,. Lancet, 350:178-181.

Frobin W, Brinckmann P, Kramer M, Hartwig E, Height of lumbar discs measured from radiographs compared with degeneration and height classified from MR images, 2001, Eur Radiol, 11:263-269

Hambly MF, Mooney V, Effect of smoking and pulsed electromagnetic fields on intradiscal pH in rabbits, 1992, Spine (Phila Pa 1976), 17(6)(Suppl):S83-5

Hastreiter D, Ozuna RM, Spector M, Regional variations in certain cellular characteristics in human lumbar intervertebral discs, including the presence of alpha-smooth muscle actin, 2001, J Orthop Res, 19:597-604

Johnstone B, Bayliss MT, The large proteoglycans of the human intervertebral disc. Changes in their biosynthesis and structure with age, topography, and pathology, 1995, Spine, 20:674-684.

Jones IA, Togashi R, Hatch GFR, Anabolic Steroids and Tendons: A Review of Their Mechanical, Structural, and Biologic Effects, November 2018, Joural of Orthopaedics Research, DOI: 10.1002/jor.24116.

Juneja SC, Schwarz EM, O'Keefe RJ, Cellular and Molecular Factors in Flexor Tendon Repair and Adhesions: A Histological and Gene Expression Analysis, 2013, Conect Tissue Res, DOI: 10.3109/03008207.2013.787418.

Kanayama G, DeLuca J, Meehan WP, Rupture Tendons in Anabolic-Androgenic Steroid User A Cross-Sectional Cohort Study, 2015, The American Journal of Sports Medicine, Vol 43, DOI: 10.1177/0363546515602010

Lyons G, Eisenstein SM, Sweet MB, Biochemical changes in intervertebral disc degeneration, 1981, Biochim Biophys Acta, 673:443453.

M. A. Palladino, F. R. Bahjat, E. A. Theodorakis, L. L. Moldawer, Nat. Rev. Drug Discov. 2, 736 (2003).

Maitre CL, Hoyland JD, Freemont AJ, Catabolic cytokine expressin in degenerate and herniated human intervertebral disc: IL-1 beta and TNF alpha expression profile, 2007, Arthritis Res Ther 